\title{
Clinical Evaluation of Pit and Fissure Sealants Placed by Undergraduate Dental Students in 5-15 Years-old Children in Iraq
}

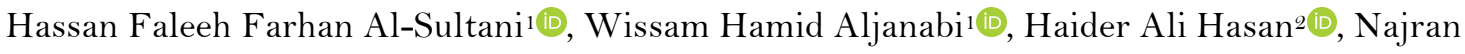 \\ Mohammed Hussain Al-Murib (D), Mohammad Khursheed Alam ${ }^{4}$
}

\begin{abstract}
${ }^{1}$ Department of Preventive, Orthodontics and Pediatric Dentistry, College of Dentistry, University of Babylon, Babylon, Iraq.

${ }^{2}$ Oral and Maxillofacial Surgery Department, College of Dentistry, University of Babylon, Babylon, Iraq.

${ }^{3}$ Ministry of Health, Babylon, Iraq.

${ }^{4}$ Orthodontic Department, College of Dentistry, Jouf University, Sakaka, Kingdom of Saudi Arabia.
\end{abstract}

Author to whom correspondence should be addressed: Dr. Hassan Faleeh Farhan AL-Sultani, College of Dentistry, University of Babylon, Iraq. Aljamea sq. 60 street. Phone: +009647727229908. E-mail: wateefihassan@gmail.com.

Academic Editors: Alessandro Leite Cavalcanti and Wilton Wilney Nascimento Padilha

Received: 17 July 2019 / Accepted: 19 October 2019 / Published: 25 October 2019

\begin{abstract}
How to cite this article: AL-Sultani HFF, Aljanabi WH, Hasan HA, Al-Murib NMH, Alam MK. Clinical evaluation of pit and fissure sealants placed by undergraduate dental students in 5-15 years-old children in Iraq. Pesqui Bras Odontopediatria Clín Integr. 2020; 20:e5110. https://doi.org/10.1590/pboci.2020.004
\end{abstract}

\begin{abstract}
Objective: To clinically evaluate the retention and marginal discoloration of pit and fissure sealants applied to primary and permanent teeth. Material and Methods: The study population encompassed of 5-15 yearsold children. After consenting, a light-curing sealant was applied to etched pits and fissures of occlusal surfaces of selected sound teeth. The retention rate and marginal discoloration were assessed, 3 months after application of the sealants based on the criteria proposed by Simonsen's criteria (total retention: score o, partial loss: score 1, and total loss: score 2). Each tooth was considered as an independent sample during analysis. Results: The achieved sample size was 43 children aged 5-15 years (mean age $=10.0$ years). Therefore, data of 100 teeth from 43 children were used for the final analysis. The percentage of completely retained sealants $(59 \%)$ was higher than the percentage of partially retained sealants $(23 \%)$ and completely missing sealants (18\%) after 3 months follow up. Out of 100 sealed teeth, $60 \%$ were either had marginal discoloration or completely missing. Using the Mann-Whitney test, there was a statistically significant difference $(\mathrm{p}<0.05)$ between primary and permanent teeth in terms of retention. However, there was no statistical difference $(\mathrm{p}>0.05)$ between upper and lower teeth in terms of retention. Conclusion: The success rate of fissure sealants after 3 months follow-up was satisfactory.
\end{abstract}

Keywords: Pit and Fissure Sealants; Dental Care for Children; Students, Dental. 


\section{Introduction}

It is well known that dental caries is the most prevalent oral disease and regarded as a public health problem [1,2]. Newly erupted primary and permanent molars are at high risk for developing dental caries due to the complex morphology of their occlusal surfaces, which involve pits and fissures [1,3,4]. Occlusal pits and fissures favor the stagnation of food debris and bacteria and facilitate the initiation of tooth decay [5].

From various preventive strategies that have been widely used in the dentistry field, sealing deep pits and fissures are an evidence-based caries preventive technique to protect the occlusal surfaces against dental caries [6]. Pit and fissure sealants were introduced in the 1960 s and have been widely used since then [4,7]. Once the protective role of the pit and fissure sealants was established, different materials of fissure sealants were introduced, such as resin-based sealants, glass ionomer-based sealants, and polyacid-modified resin-based sealants [8].

The preventive properties of pit and fissure sealants have been verified in numerous studies [3,9]. Fissure sealant can reduce the incidence of dental caries by more than half in the first five years after the application when each tooth is sealed only once with no follow-up treatment. In cases that the sealed teeth are regularly (annually, for instance) examined and the defected or lost fissure sealants are renewed, the chance of caries could be reduced by $75 \%$ up to four years [10]. Although pit and fissure sealants are regarded as efficacious preventive strategies [11], failure rates are often ranged from $5 \%$ to $10 \%$ annually [12], mostly due to poor retention of pit and fissure sealants [13,14]. One of the main reasons for the early loss of fissure sealants is the contamination of the tooth surface with saliva during their application [15]. This is of special importance as fissure sealant is usually applied to children's (who might be less cooperative) teeth, which might not be fully erupted [16]. Therefore, factors such as "stage of tooth eruption, the behavior of the child, the possibility of establishing adequate isolation by applying rubber dam or cotton roll" should be taken in consideration during the application of the sealants $[17,18]$.

To our knowledge, no study has evaluated the retention rate of pit and fissure sealants among children in Hilla city, Babylon governorate, Iraq. Therefore, this study was designed and conducted among 5 to $15-$ year-old children to assess the success rate of the pit and fissure sealants placed by undergraduate dental students to primary and permanent teeth. The aim of the current study was to clinically evaluate the retention and marginal discoloration of pit and fissure sealants applied to both dentitions.

\section{Material and Methods}

Study Design and Sample

This longitudinal study involved children aged 5-15 years, who attended to the Department of Pediatric and Preventive Dentistry, College of Dentistry, University of Babylon, Hillah city between December 2018 and March 2019.

Inclusion criteria were sound (caries-free) fully erupted primary and permanent premolars and molars with the absence of prior sealants or restorations and have intact deep and retentive fissures. Teeth with initial carious lesions or cavities were excluded from the study, and children, whom parents or guardians were unable to give consent form were also excluded from the study.

\section{Data Collection}

The children selected for the study received a preventive program including oral examination, oral hygiene instruction and motivation, prophylaxis and topical fluoride application, extraction of infected teeth, 
and restorations in addition to the application of pit and fissure sealants for one or more teeth. Fissure sealants were applied by undergraduate dental students (fifth stage) under the supervision of a specialist (i.e., Preventive and Pediatric) dentists.

The examination of teeth was done by calibrated examiners. The examiners were calibrated with an experienced dentist by examining the sealants in 10 patients (20 teeth). The same children were re-examined again by the examiners after 10 days to eliminate the chance of memory bias. During calibration, Kappa values for intra- and inter-examiner reproducibility were 0.85 and 0.93 , respectively. Information on children's age and gender, type of residential area (rural/urban), type of fissure sealant used, and method of application were obtained from the records.

The procedure of application of pit and fissure sealants involved: a) prophylaxis and polishing; b) isolation with cotton rolls; c) enamel surface pretreatment with acid etching only (conventional acid etching without adhesive) using 37 \% phosphoric acid gel (Super Etch LV, SDI Limited, Bayswater, Australia) for 30 seconds and according to manufacturer' instructions; d) rinsing of the teeth with water for 10-20 seconds and then air-dried using air syringe; e) placement of pit and fissure sealant: A light curing, resin-based, white, unfilled pit and fissure sealant (i.e., Conseal f, SDI Limited, Bayswater, Australia) was applied (based on manufacturers' instructions) to the etched pits and fissures of the occlusal surfaces; and f) crosschecking of the occlusion with articulating papers and reducing premature contacts using composite finishing burs. All sealed teeth were clinically assessed 3 months after placement of pit and fissure sealants.

The retention rate was judged based on 'Simonsen's criteria' [19] for retention of sealants: a) Total retention: total retention of the sealant on the occlusal surface (score 0); b) Partial loss: presence of sealant with fractures and loss of material (score 1); and c) Total loss: absence of the sealant on the occlusal surface (score 2).

Simonsen's criteria were described by many researchers as a simple, convenience, reliable, and valid criteria for evaluation of the retention of pit and fissure sealants [20-22]. The pattern of marginal discoloration was also checked as present or absent of the discoloration. This could provide an initial sign of marginal leakage [23].

\section{Data Analysis}

Microsoft Excel (version 2013) and Statistical Package for the Social Sciences (SPSS) statistical software (version 23) were used for data entry and analysis, respectively. Each examined tooth was considered as an independent sample during analysis. The frequency and percentage of each type of tooth condition were calculated. The condition of the examined teeth was compared between upper and lower teeth, urban and rural areas, boys and girls, caries-free children and those with caries in their other teeth at the time of evaluation of fissure sealants. Mann-Whitney test was used to assess if there is a difference in sealant retention according to jaw location and dentition type. P-values $<0.05$ were regarded as statistically significant.

\section{Ethical Aspects}

This study was approved by the Ethics Committee of the College of Dentistry, University of Babylon. Before starting the study, all parents or guardians were informed about the aim, nature, and potential distresses and benefits of the study. Then, informed consent was obtained from all of them.

\section{Results}


Out of 48 children, who participated in the study, 43 (89.6\%) participants were examined 3 months after the application of fissure sealants. Five (10.4\%) participants dropped out of the study for unknown reasons. Therefore, the achieved sample size was 43 children aged 5-15 years (mean age $=10.0$ years). Table 1 shows the demographic characteristics of the children involved in this study. Most of the children were boys $(53.5 \%)$, between 5 and 10 years $(55.8 \%)$ and living in urban areas $(62.8 \%)$.

Table 1. Demographic characteristics of the participants.

\begin{tabular}{lcc}
\hline \multicolumn{1}{c}{ Variables } & N & \% \\
\hline Gender & & \\
Boy & 23 & 53.5 \\
Girl & 20 & 46.5 \\
Age (Years) & & \\
$5-10$ & 24 & 55.8 \\
$11-15$ & 19 & 44.2 \\
Area of Residency & & \\
Urban & 27 & 62.8 \\
Rural & 16 & 37.2 \\
\hline
\end{tabular}

Table 2 illustrates the demographic variables of samples of the study. As mentioned above, each tooth was considered as an independent sample. Therefore, data of 100 teeth from 43 children were used for the final analysis. About $55 \%$ of the examined teeth were in the upper arch and $45 \%$ were in the lower arch. Most sealed teeth were permanent $(82 \%)$; while, only $(18 \%)$ of sealed teeth were primary teeth.

Table 2. Demographic characteristics of the included teeth $(\mathrm{N}=100)$.

\begin{tabular}{llll}
\hline \multicolumn{1}{c}{ Variables } & \multicolumn{1}{c}{ Categories } & $\mathbf{N}$ & \% \\
\hline Gender & Boy & 53 & 53.0 \\
\multirow{2}{*}{ Age (Years) } & Girl & 47 & 47.0 \\
\multirow{2}{*}{ Area of Residency } & $5-10$ & 56 & 56.0 \\
& $11-15$ & 44 & 44.0 \\
\multirow{2}{*}{ Jaw } & Urban & 67 & 67.0 \\
\multirow{2}{*}{ Dentition Type } & Rural & 33 & 33.0 \\
& Upper & 55 & 55.0 \\
& Lower & 45 & 45.0 \\
& Primary & 18 & 18.0 \\
\hline
\end{tabular}

Table 3 shows retention and the presence or absence of marginal discoloration three months after the placement of pit and fissure sealants. The percentage of completely retained sealants (59\%) was higher than the percentage of partially retained sealants (23\%) and completely missing sealants (18\%) after 3 months follow up. The percentage of sealed teeth with marginal discoloration (42\%) was higher than sealed teeth with no discoloration $(40 \%)$. Out of 100 examined teeth, $97 \%$ were reported as caries-free at the evaluation time. Only $3 \%$ of the examined teeth were recorded as decayed at the evaluation or examination time.

Table 3. Condition of the teeth when examined three months after fissure sealant application.

\begin{tabular}{|ccc}
\hline Condition of the FS & N & \% \\
\hline Retention [12] & & \\
Completely Retained & 59 & 59.0 \\
Partially Retained & 23 & 23.0 \\
Completely Missing & 18 & 18.0
\end{tabular}




\begin{tabular}{lcc} 
Marginal Discoloration & & \\
No Discoloration & 40 & 40.0 \\
Discolored & 42 & 42.0 \\
Not Applicable & 18 & 18.0 \\
Dental Status & & 97.0 \\
Caries Free & 97 & 3.0 \\
Caries & 3 & \\
\hline
\end{tabular}

Figure 1 illustrates the sealant retention of primary teeth and permanent teeth, three months after the placement of pit and fissure sealants. Out of 18 sealed primary teeth, 38.9\% were completely retained, $16.7 \%$ were partially retained and 44.4\% were completely missing. In addition, out of 82 sealed permanent teeth, $63.4 \%$ were completely retained, $24.4 \%$ were partially retained and $12.2 \%$ were completely missing. Using a Mann-Whitney test, there was a statistically significant difference $(\mathrm{p}<0.05)$ between primary and permanent teeth in terms of retention of pit and fissure sealants.

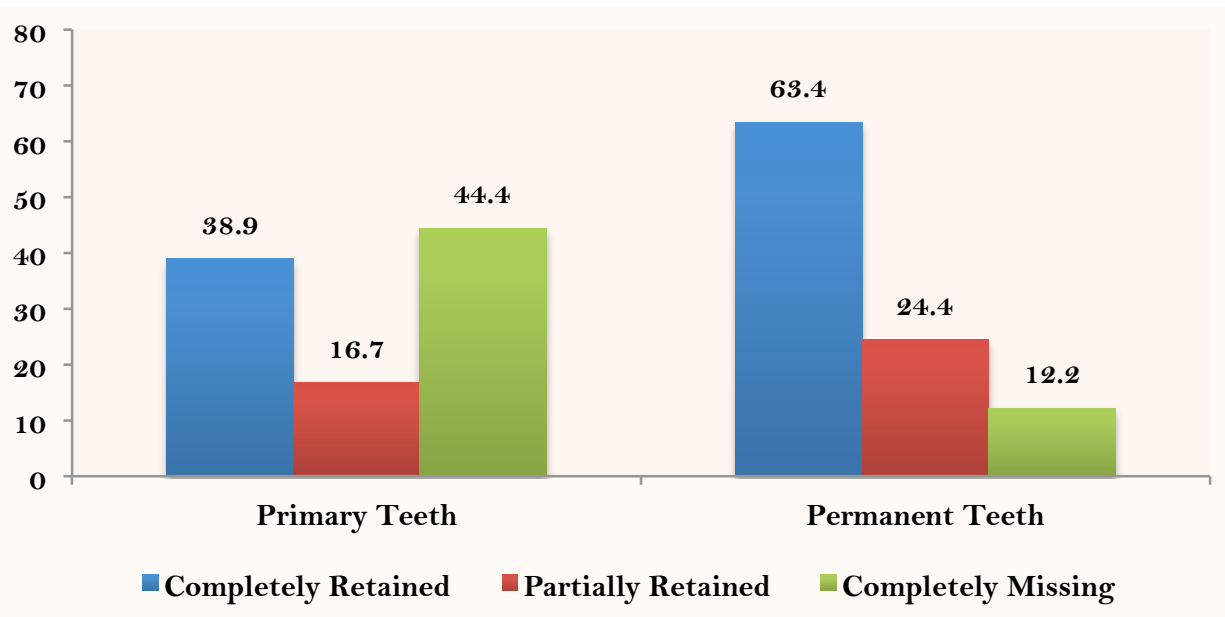

Figure 1. Retention of the sealants in primary and permanent teeth after 3 months.

Figure 2 shows the distribution of sealant retention according to the jaw location, 3 months after the application of fissure sealants. Out of 55 sealed upper teeth, $63.6 \%$ were completely retained, $14.6 \%$ were partially retained and $21.8 \%$ were completely missing. In addition, out of 45 sealed lower teeth, $53.4 \%$ were completely retained, $33.3 \%$ were partially retained and $13.3 \%$ were completely missing. Statistically, there was no significant difference $(\mathrm{p}>0.05)$ in the retention of fissure sealants between upper and lower teeth.

Table 4 illustrates the marginal discolorations at 3 months intervals by dentition type and jaw location. In general, out of 100 sealed teeth, $60 \%$ were either had marginal discoloration or completely missing. More specifically, out of 18 examined primary teeth, only $33.3 \%$ of the sealed teeth were without any marginal discoloration. The remaining of sealed teeth, $66.7 \%$ were either have marginal discoloration or fissure sealants were completely missing. In addition, out of 82 sealed permanent teeth, $41.5 \%$ of the sealed teeth were without any marginal discoloration; whereas, $58.5 \%$ of the sealed teeth were affected by marginal discoloration and completely missing of the sealants. Moreover, out of 55 sealed upper teeth, $49.1 \%$ were without any marginal discoloration, and $51.9 \%$ of the sealed teeth were either have marginal discolorations or completely missing of the fissure sealants. For the 45 sealed lower teeth, $57.8 \%$ had marginal discolorations of fissure sealants, $28.9 \%$ had no marginal discolorations and $13.3 \%$ had completely missed of fissure sealants. 


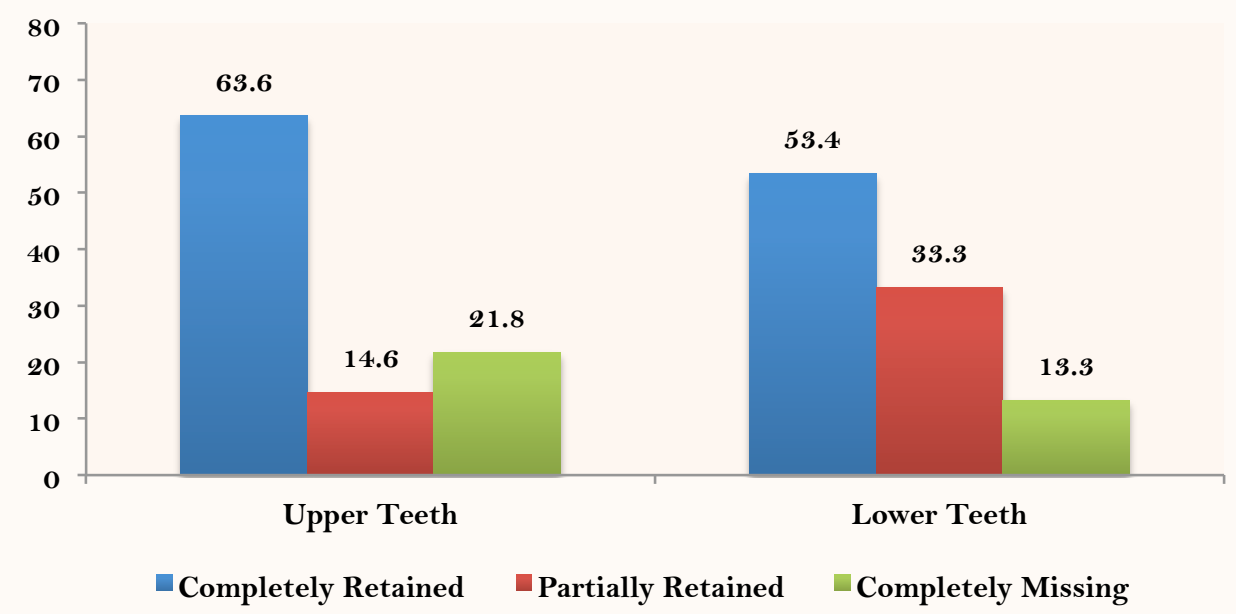

Figure 2. Distribution of sealant retention according to jaw location after 3 months.

Table 4. Marginal discoloration by dentition type and jaw location.

\begin{tabular}{|c|c|c|c|}
\hline \multirow[b]{2}{*}{ Variables } & \multicolumn{3}{|c|}{ Marginal Discoloration } \\
\hline & $\begin{array}{c}\text { Discoloration Present } \\
\text { N (\%) }\end{array}$ & $\begin{array}{c}\text { Discoloration Absent } \\
\text { N (\%) }\end{array}$ & $\begin{array}{c}\text { Completely Missing } \\
\text { N (\%) }\end{array}$ \\
\hline \multicolumn{4}{|l|}{ Dentition Type } \\
\hline Primary & $4(22.2)$ & $6(33.3)$ & $8(44.5)$ \\
\hline Permanent & $38(46.3)$ & $34(41.5)$ & $10(12.2)$ \\
\hline \multicolumn{4}{|l|}{ Jaw Location } \\
\hline Upper & $16(29.1)$ & $27(49.1)$ & $12(21.8)$ \\
\hline Lower & $26(57.8)$ & $13(28.9)$ & $6(13.3)$ \\
\hline
\end{tabular}

\section{Discussion}

In general, the rate of success of pit and fissure sealants after 3 months follow up was (59\%) indicating that sealed teeth were sound and had intact or adequate sealing after the application of pit and fissure sealants. Such finding is supported by the result that $97 \%$ of the inspected teeth were free of caries at the evaluation time. Dental caries was found only in 3 teeth during the follow-up interval. Though some teeth had a partial and complete loss of sealants, they did not develop any carious lesion, possibly due to short time of the followup interval and other factors (e.g., oral hygiene, diet, saliva), which play an important role in initiation and progression of tooth decay [24]. In addition, the low viscosity and fluoride release resin-based (unfilled) fissure sealant (Conseal f, SDI) that has been used in this study might be useful in decreasing caries incidence because it allows the deepest penetration into the deepest pits and fissures and enhances caries prevention, remineralization, and the inhibition of enamel demineralization. The unfilled resin-based sealant penetrates deeper into the micro porosities of the pits and fissures due to its low viscosity and hence, maybe better retained [25,26].

The presence $41 \%$ of teeth that had either partial or complete loss of pit and fissure sealants reveals that the failure rate of pit and fissure sealants was also high during the first 3 months after application suggesting the need for further exploration about the causes of failure and the potential techniques that could increase sealant retention. Out of 100 sealed primary and permeant teeth, $42 \%$ were with marginal discoloration indicating a loss of marginal integrity prior to additional sealant failure. Previous research has shown that failure of pit and fissure sealants is not uncommon at a baseline and 6 months after application 
[27]. Therefore, it is preferable to repeat the follow-up visits after 6 and 12 months to provide a clearer picture about the current findings.

Literature reports that inadequate isolation and contamination of pits and fissures with saliva prevent the formation of tags and thereby the mechanical retention of the resin-based sealants [28]. Therefore, it could be suggested that improper isolation and dryness of teeth using cotton rolls and triple syringe, in addition to non-usage of a rubber dam during fissure sealants application were responsible for partial and complete loss of pit and fissure sealants in the present study. In addition, the experience of undergraduate dental students in the placement of pit and fissure sealants and the collaboration of children might have an influence on sealant retention.

Sealant retention, according to dentition type, was studied comparing primary teeth with permanent teeth. In this study, retention of the sealants was more in permanent than primary teeth in which there was a statistically significant difference $(\mathrm{p}<0.05)$ in the retention of pit and fissure sealants between primary and permanent teeth. Such findings disagreed with previous research, which reported that sealants are more effective in permanent molars than primary molars, but this retention was not statistically significant [5,29,30]. Such findings may be due to morphological (e.g., shallow pits and fissures) and histological (e.g., prismless enamel) characteristics of primary teeth in comparison to permanent teeth, which can present differences in sealant retention [5]. It could be argued that young children, who have more primary teeth in their mouths are often less cooperative than older children.

Another comparison studied in the current study was sealant retention according to jaw location (i.e., upper teeth versus lower teeth). Upper teeth retained sealants better than the lower teeth, but the difference was not statistically significant $(\mathrm{p}>0.05)$. Such findings concurred with previous studies, which reported greater sealant retention in upper teeth compared to lower teeth, but without a significant difference $[5,31,32,33]$. Such findings may be attributed to relatively greater occlusal surface areas of mandibular teeth compared to maxillary teeth, which could make the sealants more exposed to the oral environment and limit their retention [34]. It could be argued that, in the absence of proper isolation (e.g., using rubber dam), lower teeth might be subjected to contamination with saliva more than upper teeth resulting in a higher percentage of sealant failure in lower teeth.

\section{Conclusion}

It was shown that the success rate of fissure sealants after 3 months follow-up was satisfactory. However, the relatively high percentages of partial and complete missing of pit and fissure sealants, in the current study, call for the need to reevaluate the preventive program in Pediatric and Preventive dental clinic thorough fully. It could be suggested that using the other types of fissure sealants (e.g., resin-modified glass ionomer-based sealants) in addition to proper isolation using, for example, a rubber dam during application of pit and fissure sealants may be useful in increasing the retention and reducing marginal discoloration of the sealed teeth. Through careful use of pit and fissure sealants, the morphology of the tooth could be altered, and the proven ecological niches of Streptococcus mutants can be removed. Hence, the goal of the primary level of prevention, which is preventing dental caries before its occurrence, can be achieved.

\section{Authors' Contributions}

HFFA (D) 0000-0002-3247-8194 Conceptualization, Methodology, Investigation, Formal Analysis, Writing Original Draft Preparation and Writing - Review and Editing. 


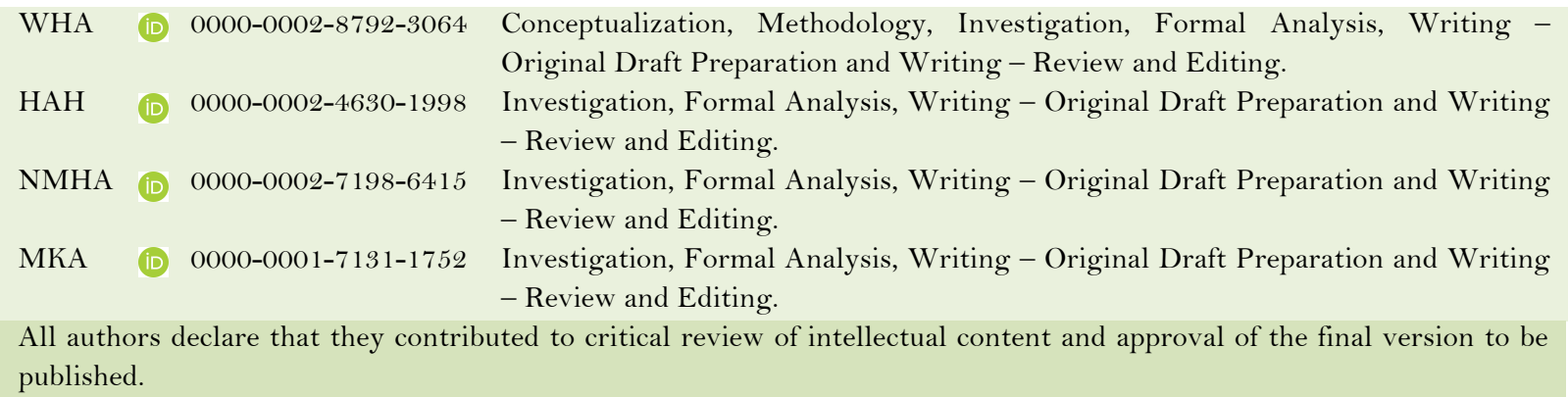

\section{Financial Support}

None.

\section{Conflict of Interest}

The authors declare no conflicts of interest.

\section{References}

[1] Nogourani MK, Janghorbani M, Khadem P, Jadidi Z, Jalali S. A 12-month clinical evaluation of pit-and-fissure sealants placed with and without etch-and-rinse and self-etch adhesive systems in newly-erupted teeth. J Appl Oral Sci 2012; 20(3):352-6. https://doi.org/10.1590/s1678-77572012000300010

[2] Dye BA, Thornton-Evans G, Li X, Iafolla TJ. Dental caries and sealant prevalence in children and adolescents in the United States, 2011-2012. NCHS Data Brief 2015; 191:1-8.

[3] Dennison JB, Straffon LH, Smith RC. Effectiveness of sealant treatment: over five years in an insured population. J Am Dent Assoc 2000; 131(5):597-605. https://doi.org/10.14219/jada.archive.2000.0233

[4] Carvalho JC, Dige I, Machiulskiene V, Qvist V, Bakhshandeh A, Fatturi-Parolo C, et al. Occlusal caries: biological approach for its diagnosis and management. Caries Res 2016; 50(6):527-42. https://doi.org/10.1 159/000448662

[5] Bhushan U, Goswami M. Evaluation of retention of pit and fissure sealants placed with and without air abrasion pretreatment in 6-8-year-old children - An in vivo study. J Clin Exp Dent 2017; 9(2):e211-e217. https://doi.org/10.4317/jced.53259

[6] Wendt LK, Koch G, Birkhed D. On the retention and effectiveness of fissure sealant in permanent molars after 15-20 years: a cohort study. Community Dent Oral Epidemiol 2001; 29(4):302-7. https://doi.org/10.1034/j.1600-0528.2001.290410.x

[7] Takeuchi M. Sealing of the pit and fissure with resin adhesive. 3. Outlines of its progress to the present time. Jpn Dent J 1967; 4:33-46.

[8] Naaman R, El-Housseiny AA, Alamoudi N. The use of pit and fissure sealants - A literature review. Dent J 2017; 5(4):E34. https://doi.org/10.3390/dj5040034

[9] Wright JT, Tampi MP, Graham L, Estrich C, Crall JJ, Fontana M, et al. Sealants for preventing and arresting pitand-fissure occlusal caries in primary and permanent molars. Pediatr Dent 2016; 38(4):282-308.

[10] Hicks M, Flaitz CM. Fissure sealants and conservative adhesive restoration: Scientific and clinical rationale. In: Pinkham JR, Casamassimo PS, Fields HW, McTique DJ, Nowak A (Eds.) Pediatric Dentistry: Infancy Through Adolescence. $4^{\text {th. }}$ ed. St. Louis: WB Saunders; 2005. p. 522-576.

[11] Bakhtiar M, Azadi N, Golkari A. A one-year evaluation of a free fissure sealant program. J Dent Biomater 2016; $3(4): 306-14$.

[12] Simonsen RJ. Pit and fissure sealant: review of the literature. Pediatr Dent 2002; 24(5):393-414

[13] Kanellis MJ, Warren JJ, Levy SM. A comparison of sealant placement techniques and 12-month retention rates. J Public Health Dent 2000; 60(1):53-6. https://doi.org/10.1111/j.1752-7325.2000.tb03293.x

[14] De Luca-Fraga LR, Pimenta LA. Clinical evaluation of glass ionomer/resin-based hybrid materials used as pit and fissure sealants. Quintessence Int 2001; 32(6):463-8.

[15] Azarpazhooh A, Main PA. Pit and fissure sealants in the prevention of dental caries in children and adolescents: a systematic review. J Can Dent Assoc 2008; 74(2):171-7.

[16] Correr GM, Caldo-Teixeira AS, Alonso RC, Puppin-Rontani RM, Sinhoreti MA, Correr-Sobrinho L. Effect of saliva contamination and re-etching time on the shear bond strength of a pit and fissure sealant. J Appl Oral Sci 2004; 12(3):200-4. https://doi.org/10.1590/s1678-77572004000300007

[17] El-Kalla IH, Garcia-Godoy F. Effect of saliva contamination on micromorphological adaptation of single-bottle adhesives to etched enamel. J Clin Pediatr Dent 1999; 24(1):69-74. 
[18] Eminkahyagil N, Gokalp S, Korkmaz Y, Baseren M, Karabulut E. Sealant and composite bond strength to enamel with antibacterial/self-etching adhesives. Int J Paediatr Dent 2005; 15(4):274-81. https://doi.org/10.1111/j.1365-263X.2005.00654.x

[19] Simonsen RJ. Retention and effectiveness of dental sealant after 15 years. J Am Dent Assoc 1991; 122(10):34-42. https://doi.org/10.14219/jada.archive.1991.0289

[20] Garrocho-Rangel A, Lozano-Vázquez C, Butron-Tellez-Giron C, Escobar-García D, Ruíz-Rodriguez S, PozosGuillen A. In vitro assessment of retention and microleakage in pit and fissure sealants following enamel pre-etching with sodium hypochlorite deproteinisation. Eur J Paediatr Dent 2015; 16(3):212-6.

[21] Reddy VR, Chowdhary N, Mukunda KS, Kiran NK, Kavyarani BS, Pradeep MC. Retention of resin-based filled and unfilled pit and fissure sealants: a comparative clinical study. Contemp Clin Dent 2015; 6(Suppl 1):S18-23. https://doi.org/10.4103/0976-237X.152932

[22] Subramaniam P, Konde S, Mandanna DK. Retention of a resin-based sealant and a glass ionomer used as a fissure sealant: a comparative clinical study. J Indian Soc Pedod Prev Dent 2008; 26(3):114-20.

[23] Khare M, Suprabha BS, Shenoy R, Rao A. Evaluation of pit-and-fissure sealants placed with four different bonding protocols: a randomized clinical trial. Int J Paediatr Dent 2017; 27(6):444-53. https://doi.org/10.1111/ipd.12281

[24] Pinar A, Sepet E, Aren G, Bölükbaşi N, Ulukapi H, Turan N. Clinical performance of sealants with and without a bonding agent. Quintessence Int 2005; 36(5):355-60.

[25] Rock WP, Weatherill S, Anderson RJ. Retention of three fissure sealant resins. The effects of etching agent and curing method. Results over 3 years. Br Dent J 1990; 168(8):323-5.

[26] Yildiz E, Dorter C, Efes B, Koray F. A comparative study of two fissure sealants: a 2-year clinical follow-up. J Oral Rehabil 2004; 31(10):979-84. https://doi.org/10.1111/j.1365-2842.2004.01334.x

[27] Kumaran P. Clinical evaluation of the retention of different pit and fissure sealants: a 1-year study. Int J Clin Pediatr Dent 2013; 6(3):183-7. https://doi.org/10.5005/jp-journals-10005-1215

[28] Morphis TL, Toumba KJ. Retention of two fluoride pit and fissure sealants in comparison to a conventional sealant. Int J Pediatr Dent 1998; 8(3):203-8.

[29] Feigal RJ. The use of pit and fissure sealants. Pediatr Dent 2002; 24:415-22.

[30] Doyle W, Brose J. A five-year study on the longevity of fissure sealants. ASDC J Dent Child 1978 45(2):127-9.

[31] Burt BA, Berman DS, Gelbier S, Silverstone LM. Retention of a fissure sealant six months after application. Br Dent J 1975; 138(3):98-100.

[32] Whitehurst V, Soni NN. Adhesive sealant clinical trial: results eighteen months after one application. J Prev Dent 1976; 3(3 Pt 2):20-2.

[33] McCune RJ, Bojanini J, Abodeely RA. Effectiveness of a pit and fissure sealant in the prevention of caries: three-year clinical results. J Am Dent Assoc 1979; 99(4):619-23. https://doi.org/10.14219/jada.archive.1979.0344

[34] Baca P, Bravo M, Baca AP, Jimenez A, Gonzalez-Rodríguez MP. Retention of three fissure sealants and a dentin bonding system used as fissure sealant in caries prevention: 12-month follow-up results. Med Oral Patol Oral Cir Bucal 2007; 12(6):E459-63. 